\title{
Heat storage with an incongruently melting salt hydrate as storage medium based on the extra water principle
}

\author{
Furbo, Simon
}

Publication date:

1980

Document Version

Publisher's PDF, also known as Version of record

Link back to DTU Orbit

Citation (APA):

Furbo, S. (1980). Heat storage with an incongruently melting salt hydrate as storage medium based on the extra water principle. Technical University of Denmark, Department of Civil Engineering.

\section{General rights}

Copyright and moral rights for the publications made accessible in the public portal are retained by the authors and/or other copyright owners and it is a condition of accessing publications that users recognise and abide by the legal requirements associated with these rights.

- Users may download and print one copy of any publication from the public portal for the purpose of private study or research.

- You may not further distribute the material or use it for any profit-making activity or commercial gain

- You may freely distribute the URL identifying the publication in the public portal

If you believe that this document breaches copyright please contact us providing details, and we will remove access to the work immediately and investigate your claim. 


\title{
HEAT STORAGE WITH AN INCONGRUENTLY MELTING SALT HYDRATE AS STORAGE MEDIUM BASED ON THE EXTRA WATER PRINCIPLE
}

\author{
SIMON FURBO \\ DECEMBER 1980
}

THERMAL INSULATION LABORATORY

TECHNICAL UNIVERSITY OF DENMARK

MEDDELELSE NR, 108 


\section{$\underline{\text { PREFACE }}$}

$R$ \& $D$ of small heat stores is one of the projects sponsored by the Danish Ministry of Energy. The project is devoted to theoretical and experimental studies to evaluate heat stores which are suitable for Danish conditions.

The project is carried out by the Thermal Insulation Laboratory, the Technical University of Denmark, in cooperation with interested institutes and industries.

The project running in the period 1978-1981 consists of the following tasks:

Heat storage in:
a) Water
b) Pebble beds
c) Latent heat stores
d) Building constructions
e) Chemical reactants
f) Water bassins (seasonal storaging)
g) Soil

The project aims at obtaining results which can be used in practice on the short view. 


\section{ABSTRACT}

The extra water principle, a heat of fusion storage method which was suggested in 1975 at the Thermal Insulation Iaboratory, the Technical University of Denmark, is shortly described. The extra water principle makes it possible to use an inorganic, incongruently melting salt hydrate as a reliable and stable storage medium in an inexpensive way.

Different heat storages making use of the extra water principle are described. An example is given of the advantages by using a heat of fusion storage unit based on $\mathrm{Na}_{2} \mathrm{~S}_{2} \mathrm{O}_{3} \cdot 5 \mathrm{H}_{2} \mathrm{O}$ and the extra water principle instead of a traditional hot water tank in small solar heating systems for domestic hot water supply.

The advantage by using such a heat storage instead of a hot water storage is the great heat storage capacity which involves small demands for storage volume. Further, in small solar heating systems the heat of fusion storage is able to supply all the wanted hot water in the summer during longer periods than an ordinary hot water storage. Therefore the heat of fusion storage is particularly favourable in domestic hot water supply systems with an auxiliary energy source which during the summer have a large energy consumption compared with the energy demands for the hot water supply. 
Storage material -

The phase separation problem - 2

The extra water principle

Experiments - 6

An example of the advantages by using heat of fusion storages in solar heating systems for

domestic hot water supply

Conclusion -

Litterature references -

Project organization - 16

Iist of published reports

List of tables:

Table 1. Data for salt hydrates which are attractive as heat storage materials in connection with solar heating systems -...- 1

Table 2. Assumptions used in the calculations ---- 11

\section{List of figures:}

Figure 1. Heat storage capacity in the temperature interval $0-1000 \mathrm{C}$ of an ideal working incongruently melting salt hydrate, a salt water mixture based on the extra water principle, and water. The anhydrous salt is $\mathrm{Na}_{2} \mathrm{SO}_{4} \cdot \ldots$

Figure 2. Heat storage capacity of different heat storage materials -

Eigure 3. Schematical illustration of 3 heat storages - - -

Figure 4. Schematical illustration of the solar heating systems with a hot water storage and a heat of fusion storage --n-n-- 10

Figure 5. Utilized yearly solar energy from $6 \mathrm{~m}^{2}$ solar heating systems for domestic hot water supply as a function of storage type and storage volume

Figure 6. Yearly utilized solar energy per cost of investment for a $6 \mathrm{~m}^{2}$ solar heating system as a function of storage type and storage volume 
Storage material

Heat of fusion storage material candidates are: inorganic congruently melting salt hydrates, incongruentiy melting salt hydrates where phase separation is avoided, organic compounds, and organic and inorganic eutectic mixtures. As a rule the organic compounds have small densities compared with the inorganic salt hydrates resulting in a small storage density per unit volume. This makes the salt hydrates favourable as heat storage materials. Harmless inexpensive salt hydrates with melting points in the temperature interval $25-70^{\circ} \mathrm{C}$ and high heat of fusions are attractive as heat of fusion storage materials in connection with solar heating systems. Examples of such salt hyarates are listed in table 1. The melting point, the heat of fusion, the price for large cuantities as well as the melting behaviour are indicated. Since almost all salt hydrates which are attractive as heat storage materials melt incongruently, it is important to solve the phase separation problem which is connected to the use of incongruently melting salt hydrates.

\begin{tabular}{|c|c|c|c|c|}
\hline Formula & $\begin{array}{l}\text { Melting } \\
\text { point, }{ }^{\circ} \mathrm{C}\end{array}$ & $\begin{array}{l}\text { Heat of fusion } \\
\mathrm{kJ} / \mathrm{kg} \text { salt } \\
\text { hyarate }\end{array}$ & $\begin{array}{l}\text { Price } \\
\text { Dkr/kg salt } \\
\text { hydrate } \\
20 t \text { delivery } \\
I \$=5.8 \text { Dkr }\end{array}$ & $\begin{array}{l}\text { Congruent } \\
\text { melting }\end{array}$ \\
\hline & & 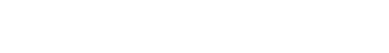 & & \\
\hline $\mathrm{Na}_{3} \mathrm{PO}_{4} \cdot 12 \mathrm{H}_{2} \mathrm{O}$ & 65 & 190 & 1.80 & no \\
\hline $\mathrm{NaCH}_{3} \mathrm{COO} \cdot 3 \mathrm{H}_{2} \mathrm{O}$ & 58 & 265 & 2.10 & no \\
\hline $\mathrm{Na}_{2} \mathrm{~S}_{2} \mathrm{O}_{3} \cdot 5 \mathrm{H}_{2} \mathrm{O}$ & 48 & 209 & 1.45 & no \\
\hline $\mathrm{Ca}\left(\mathrm{NO}_{3}\right)_{2} \cdot 4 \mathrm{H}_{2} \mathrm{O}$ & 43 & 153 & 0.75 & no \\
\hline $\mathrm{Na}_{2} \mathrm{HPO}_{4} \cdot 12 \mathrm{H}_{2} \mathrm{O}$ & 35 & 266 & 1.90 & no \\
\hline $\mathrm{Na}_{2} \mathrm{CO}_{3} \cdot 1 \mathrm{OH}_{2} \mathrm{O}$ & 33 & 247 & 0.45 & no \\
\hline $\mathrm{Na}_{2} \mathrm{SO}_{4} \cdot 1 \mathrm{OH}_{2} \mathrm{O}$ & 32 & 251 & 0.40 & no \\
\hline $\mathrm{CaCl}_{2} \cdot 6 \mathrm{H}_{2} \mathrm{O}$ & 29 & 174 & 1.10 & no \\
\hline
\end{tabular}

Table 1. Data for salt hydrates which are attractive as heat storage materials in connection with solar heating systems. 


\section{The phase separation problem}

An incongruently melting salt hydrate consists of an anhydrous salt with corresponding crystal water. The solubility of the anhydrous salt in water at the melting point is not great enough to dissolve all the anhydrous salt in the corresponding crystal water. The molten salt hydrate therefore consists of a saturated solution and some anhydrous salt undissolved in the water. When nothing is done this results in sedimentation in the storage tank due to the higher density. By cooling, salt hydrate crystals are formed in the dividing line between sediment and solution, by which a solid crust is formed. This solid crust prevents the anhydrous salt at the bottom and the upper layer of saturated solution from getting in contact. Only a part of the anhydrous salt in the solution is active in the phase change, and the salt hydrate consists of three parts at temperatures lower than the melting point: at the bottom the anhydrous salt, then a layer of solid salt hydrate crystals, and at the top a layer of saturated salt solution. If the salt hydrate is not stirred, the salt hydrate crystals will melt by heating and form a supersaturated solution. The amount of sediment increases, and the heat storage capacity decreases by each melting/crystallization cycle, and due to that the phase separation has to be avoided before it is possible to make use of an incongruently melting salt hydrate as a reliable heat storage medium.

\section{The extra water principle}

The extra water principle is a method which prevents phase separation, thus resulting in a stable heat of fusion storage using an incongruently melting salt hydrate as storage meaterial. The method is described in detail in [1] and [2].

The method consists in adding extra water to the salt hydrate so that all the anhydrous salt can be dissolved in the water at the melting point, that is, the storage medium is a saturated salt solution at the melting point. The storage medium is stirred softly while it is cooled or heated. Since crystalliza- 
tion only takes place from a saturated solution, and the solubility of the salt in water for temperatures below the melting point decreases for decreasing temperatures, solidification takes place by decreasing temperatures. For temperatures below the melting point the storage medium consists of a salt hydrate solid phase and a saturated solution. By heating, some of the solid salt hydrate melts, and due to the soft stirring the solution will still be saturated also at the higher temperature, so that the mixture will remain stable. The soft stirring is necessary due to differences in density between the salt solution and the melted salt hydrates. The stirring could be natural convection caused by temperature differences inside the heat storage as well as forced convection produced by a stirrer. Both melting and solidification take place in the temperature interval from the melting point and downwards. The heat of fusion of the storage medium is situated in the same temperature interval. The heat storage capacity of the storage medium is less than that of the ideal working incongruently melting salt hydrate, since only a part of the anhydrous salt in the salt water mixture is active in the phase change. on the other hand the heat storage remains stable.

In the temperature interval $0-1000^{\circ} \mathrm{C}$ figure 1 shows the theoretical heat storage capacity of an incongruently melting salt hydrate, Glauber's salt, if it could work stably. The heat storage capacity of a salt water mixture consisting of $33 \% \mathrm{Na}_{2} \mathrm{SO}_{4}$ and $67 \%$ of water based on weight, that is a storage medium making use of Glauber's salt and the extra water principle, and the heat capacity of water is shown too. The ratio between the heat storage capacity of a salt water mixture and that of water depends on the temperature interval which is chosen for the comparison. For small temperature intervals around the melting point the ratio is great, and for increasing temperature intervals the ratio decreases. 


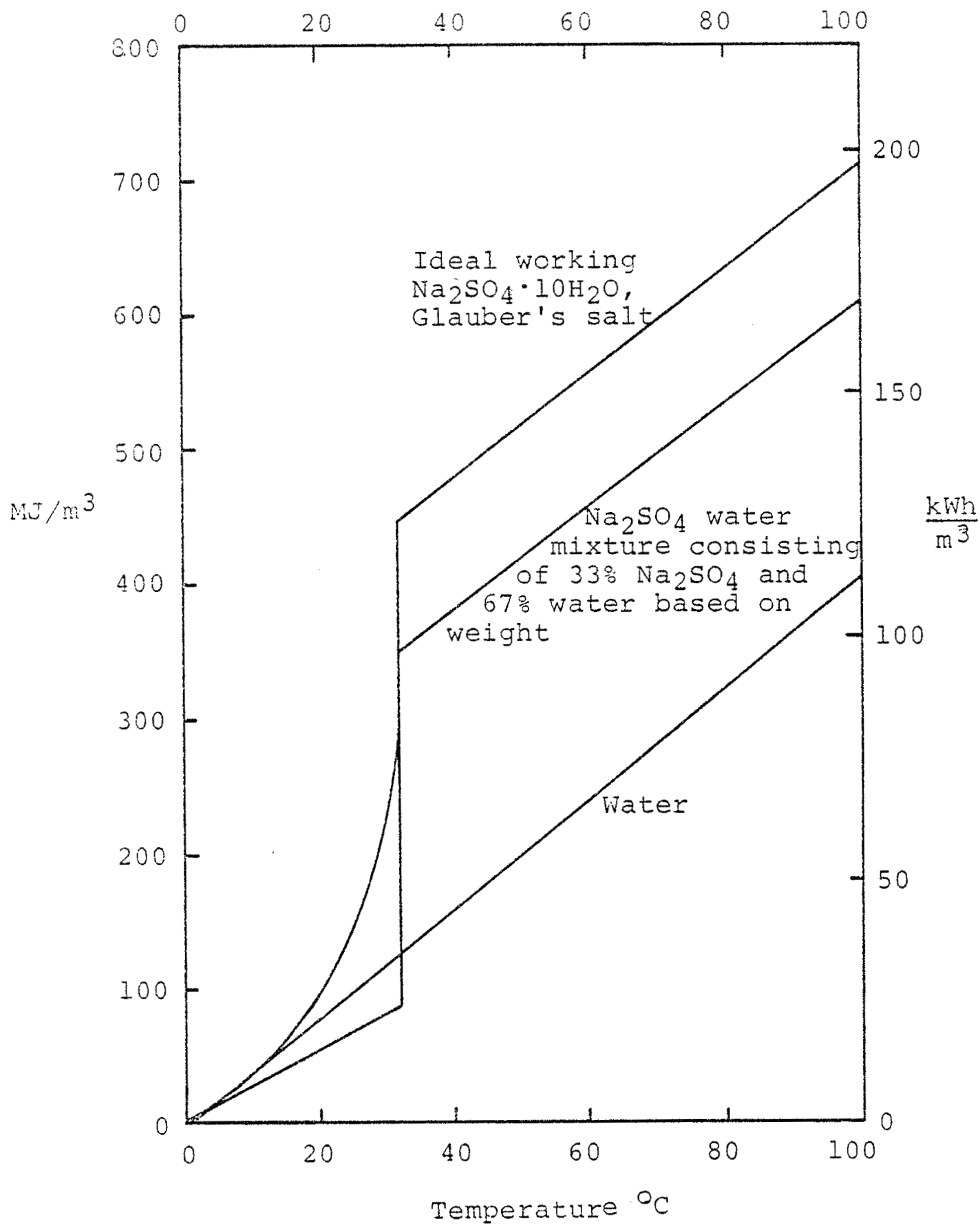

Figure 1. Heat storage capacity in the temperature interval $0-100^{\circ} \mathrm{C}$ of an ideal working incongruently melting salt hydrate, a salt water mixture based on the extra water principle, and water. The anhydrous salt is $\mathrm{Na}_{2} \mathrm{SO}_{4}$. 
Figure 2 shows the heat storage capacity in the temperature interval $0-100^{\circ} \mathrm{C}$ for five inexpensive, incongruently melting salt hydrates from table 1 , with different melting points making use of the extra water principle. The salt hydrates are attractive as storage medium in different systems: salt hydrates with high melting points in systems demanding high temperatures, salt hydrates with low melting points in systems demanding low temperatures.

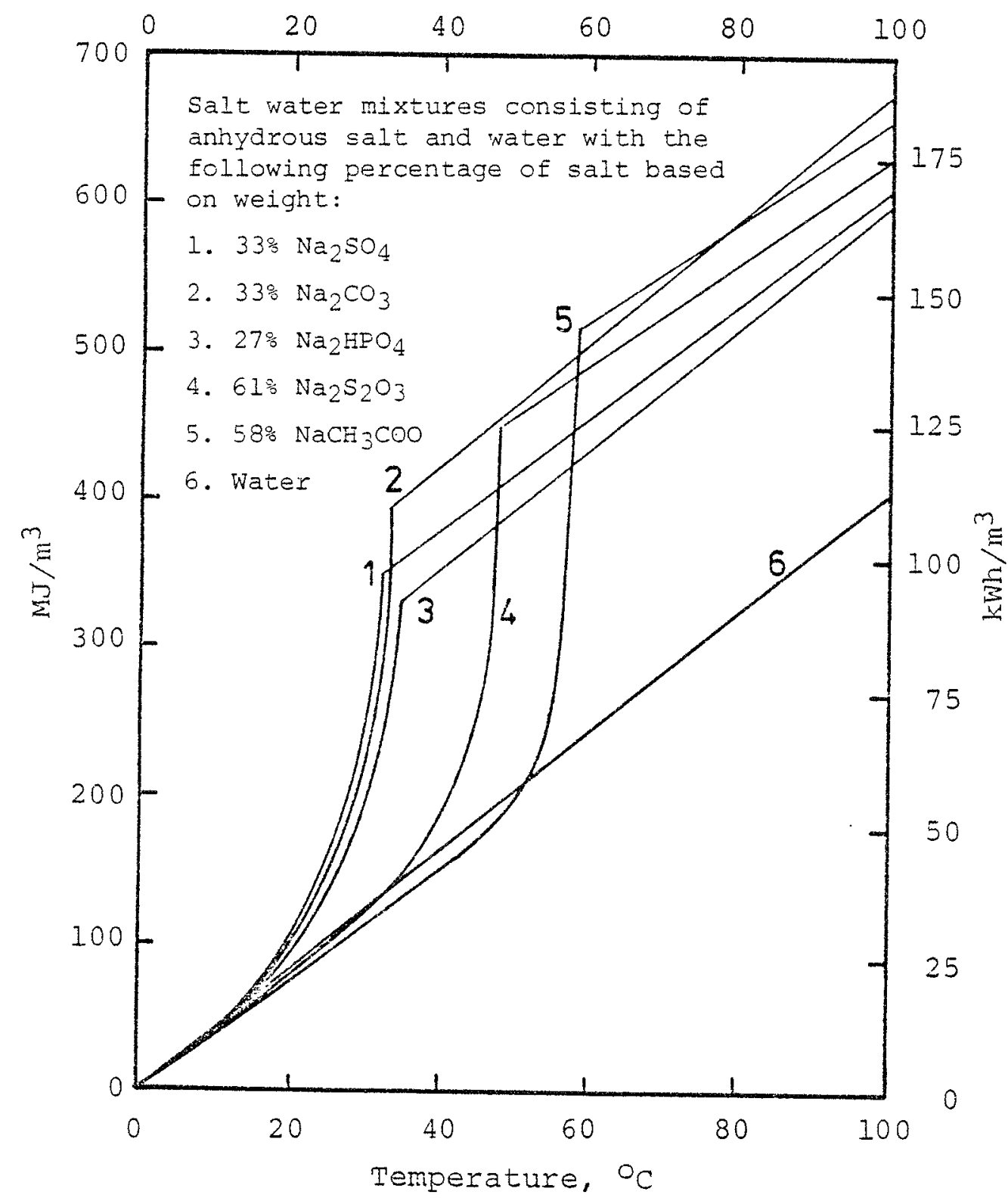

Figure 2. Heat storage capacity of different heat storage materials. 


\section{Experiments}

During the last 5 years several storage units making use of the extra water principle with different salt hyarates have been tested, running both long and short term experiments.

The main result of the long term experiments making use of the extra water principle is, that the unstability caused by phase separation is avoided resulting in reliable and stable heat of fusion storages.

Important problems concerning salt hydrate storages based on the extra water principle are: heat transfer problems caused by the poor thermal conductivity of the solid salt hydrate crystals, super cooling problems, and salt water mixture stirring problems. These problems must be solved by an inexpensive and proper heat storage design.

Figure 3 shows schematical illustrations of 3 storage types which have been tested. In the first type the heat transfer problems are solved due to the direct contact between the heat transfer and the heat storage medium. Oil is the heat transfer medium, which is circulated in an inner cirquit through a heat exchanger where heat is transferred to or from the storage. The oil must be completely immiscible with the salt water mixture. Due to density differences the oil will form a layer at the top of the storage tank. The oil is conducted in a pipe to the bottom of the container and through a nozzle system to the salt water mixture. The oil drops take care of the stirring, and the stirring prevents supercooling. The storage can be used in connection with solar heating systems for space heating and domestic hot water supply. The experiments showed that it is difficult to maintain the separation between the oil layer and the salt water mixture when the oil flow rate is great. Since additionally crystal growth in the nozzles appears for low temperatures, the heat transfer from the storage to the oil will be poor for low temperatures. Further the heat storage system will be rather expensive due to the oil, the heat exchanger, the nozzle system and the oil pump. 

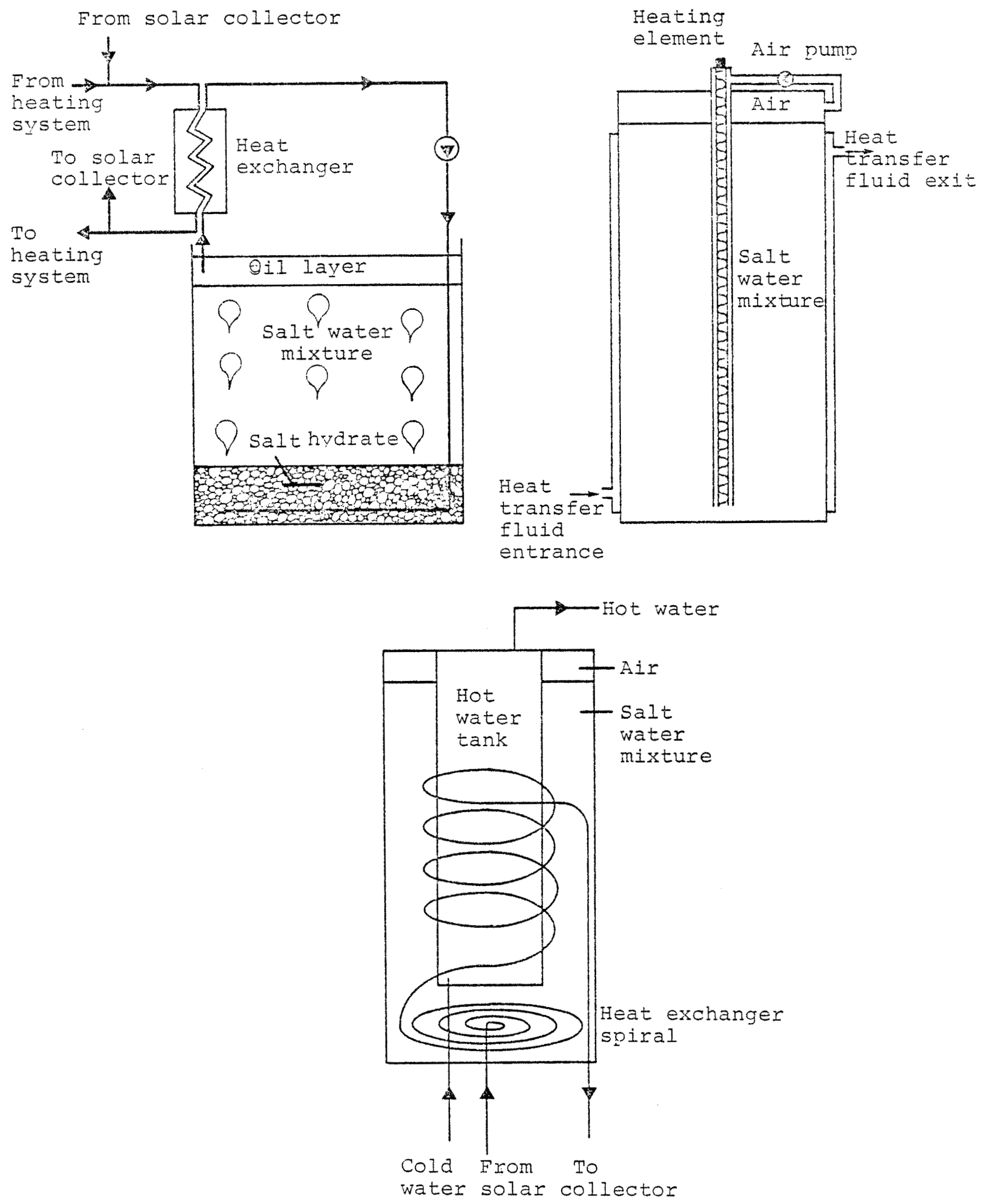

Figure 3. Schematical illustration of 3 heat storages. 
In the second type the fluid, which transfers heat to and from the storage, is the solar collector fluid. The fluid is circulated in a mantle around the surface of the storage tank. The heat is conducted through the container wall to and from the storage medium. The top of the tank serves as expansion possibility, and the tank is closed. Air situated at the top of the container is conducted through a pipe to the bottom of the container by use of an air pump, and the air bubbling through the salt water mixture produces a soft stirring. A heating element situated in the pipe takes care of any salt hydrate crystals which prevent the circulation of the air. The storage can be used in connection with solar heating systems for space heating and domestic hot water supply. The heat transfer from the storage to the heat transfer fluid and the price of the heat storage are of reasonable amounts. Therefore this storage system is favourable compared with the storage with oil as the heat transfer fluid.

In the third type a hot water tank is situated inside a tank in which the salt water mixture is situated. Heat from the solar collector is transferred to the storage by use of a heat exchanger spiral in which the solar collector fluid is conducted. The heat exchanger spiral is situated at the bottom of the storagie tank and around the bottom of the hot water tank. While cold water enters the bottom of the hot water tank a part of the solution is cooled, and a soft stirring of the salt solution caused by temperature differences occurs. The heat transfer area between the salt solution and the hot water tank is large, resulting in reasonably good heat transfer from the salt solution to the water. The storage can be used in connection with solar heating systems for domestic hot water supply. The heat storage works. as planned, when the heat exchanger spiral is situated at the bottom of the storage tank, so that all the salt hydrate crystals melt during heating before the temperature of the upper part of the salt solution has risen. During the next year this storage type will be studied carefully with different salt water mixtures as heat storage materials. 
An example of the advantages by using heat of fusion storages in solar heating systems for domestic hot water supply

The yearly thermal performance of small solar heating systems for domestic hot water supply is found by use of computer calculations. The solar heating systems which are used in the calculations are shown schematically in figure 4. Two different storage types are used: a traditional hot water storage and a heat of fusion storage making use of a $\mathrm{Na}_{2} \mathrm{~S}_{2} \mathrm{O}_{3}$ water mixture as storage material based on the extra water principle.

The computer program simulates the solar heating system. On the basis of the data of the Danish Test Reference Year (1980 version) the solar radiation and the heat balance for the heat storage is calculated every half hour. The three parts in the heat balance are: the useful solar energy from the solar collector cirquit, the heat for the hot water consumption and the thermal loss from the heat storage to the environment. For every half hour these amounts of heat are calculated, and they are summed up for the year, and the yearly thermal performance of the solar heating system is found.

Some of the results of the calculations, with the assumptions listed in table 2, are given in figure 5. The total utilized yearly solar energy from the solar heating system consists of the net utilized solar energy and the saved thermal loss from the oil fired boiler in the summertime, where the oil burner can be turned off.

The difference between the yearly net utilized solar energy from solar heating systems with $\mathrm{Na}_{2} \mathrm{~S}_{2} \mathrm{O}_{3}$ water mixture storages and with hot water storages is small. For solar heating systems with the same yearly net utilized solar energy the volume of a hot water storage will be about twice as big as for a $\mathrm{Na}_{2} \mathrm{~S}_{2} \mathrm{O}_{3}$ water mixture storage. Almost all the increase in the yearly net utilized solar energy by using a $\mathrm{Na}_{2} \mathrm{~S}_{2} \mathrm{O}_{3}$ water storage instead of a water storage is found in the summer months, where well insulated houses have no space heating demands. When the auxiliary energy source is an oil burner this fact is important 

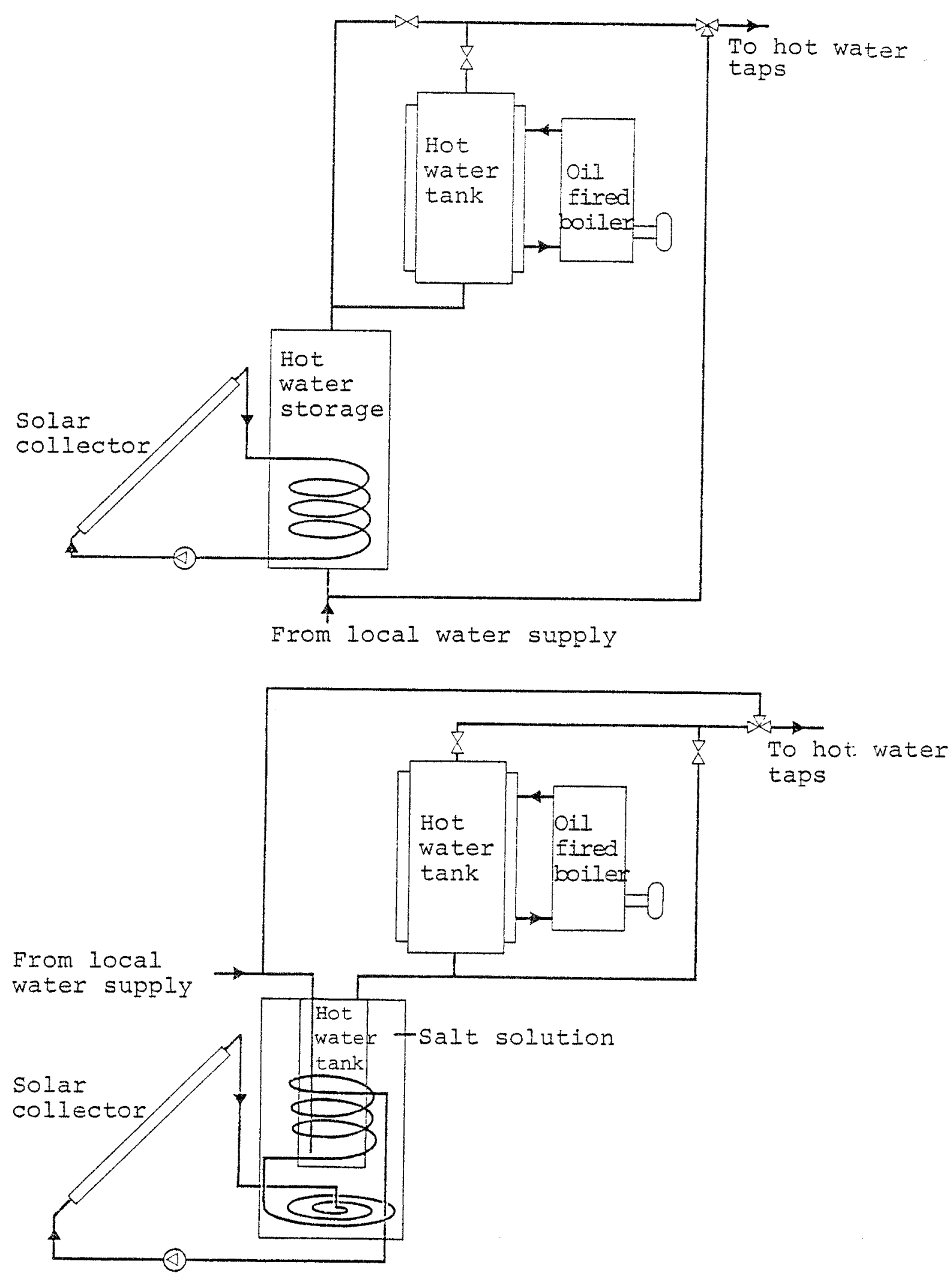

Fioure 4. Schematical illustration of the solar heating systems with a hot water storage and a heat of fusion storage. 
Solar collector:

Efficiency for small angles of incidence:

$$
\begin{aligned}
& \eta=0.80-5.5 \frac{\mathrm{T}_{\mathrm{m}}-\mathrm{T}_{\mathrm{a}}}{\mathrm{I}} \\
& \mathrm{T}_{\mathrm{m}} \text { is the temperature of the solar collector fluid } \\
& \mathrm{T} \text { in the solar collector, }{ }^{\circ} \mathrm{C} \\
& \mathrm{T}_{\mathrm{I}} \text { is the ambient temperature, }{ }^{\circ} \mathrm{C} \\
& \text { is the solar radiation on the solar collector, } \mathrm{W} / \mathrm{m}^{2}
\end{aligned}
$$$$
\text { Tilt: } 45^{\circ}
$$

Orientation: Facing south

Solar collector fluid: Glycol/water solution anti-freezed

Area: $6 \mathrm{~m}^{2}$ down to $-200^{\circ} \mathrm{C}$

Solar collector fluid rate: $61 / \mathrm{min}$

Heat storage:

Hot_water

Storage material: Water

Partly $\mathrm{Na}_{2} \mathrm{~S}_{2} \mathrm{O}_{3}$ water mixture consisting of $61 \% \mathrm{Na}_{2} \mathrm{~S}_{2} \mathrm{O}_{3}$ and $39 \%$ water based on weight, partly 1001 water situated in a hot water tank inside the storage tank.

Form:

Cylindrical tank

Cylindrical tank

Insulation: $5 \mathrm{~cm}$ of mineral wool

Thermal bridges: None $5 \mathrm{~cm}$ of mineral wool Stratification: None None None

Heat transfer power per ${ }^{\circ} \mathrm{C}$ temp.dif. between the storage and the solar collector fluid:

$$
\begin{aligned}
& 200+ 5 \cdot \mathrm{T}_{\mathrm{S}} \mathrm{W} /{ }^{\circ} \mathrm{C} \quad 200+5 \cdot \mathrm{T}_{\mathrm{S}} \mathrm{W} /{ }^{\circ} \mathrm{C} \\
& \mathrm{T}_{\mathrm{S}} \text { is the storage temperature, }{ }^{\circ} \mathrm{C}
\end{aligned}
$$

Pipes in the solar collector cirquit:

Material: Steel

Dimension: $3 / 4$ "

Insulation: $3 \mathrm{~cm}$ of mineral wool

Length: $\quad 6 \mathrm{~m}$ indoor at $20^{\circ} \mathrm{C}$

$10 \mathrm{~m}$ outside the house

Hot water consumption:

Daily consumption: 2001 water at $45^{\circ} \mathrm{C}$

Cold inlet water temperature: $10^{\circ} \mathrm{C}$

Auxiliary energy source:

Efficiency of the oil fired boiler: 0,85

Thermal loss of the boiler:

Heating value of oil:

$350 \mathrm{~W}$

$9.84 \mathrm{kWh} / \mathrm{l}$ oil

Table 2. Assumptions used in the calculations. 


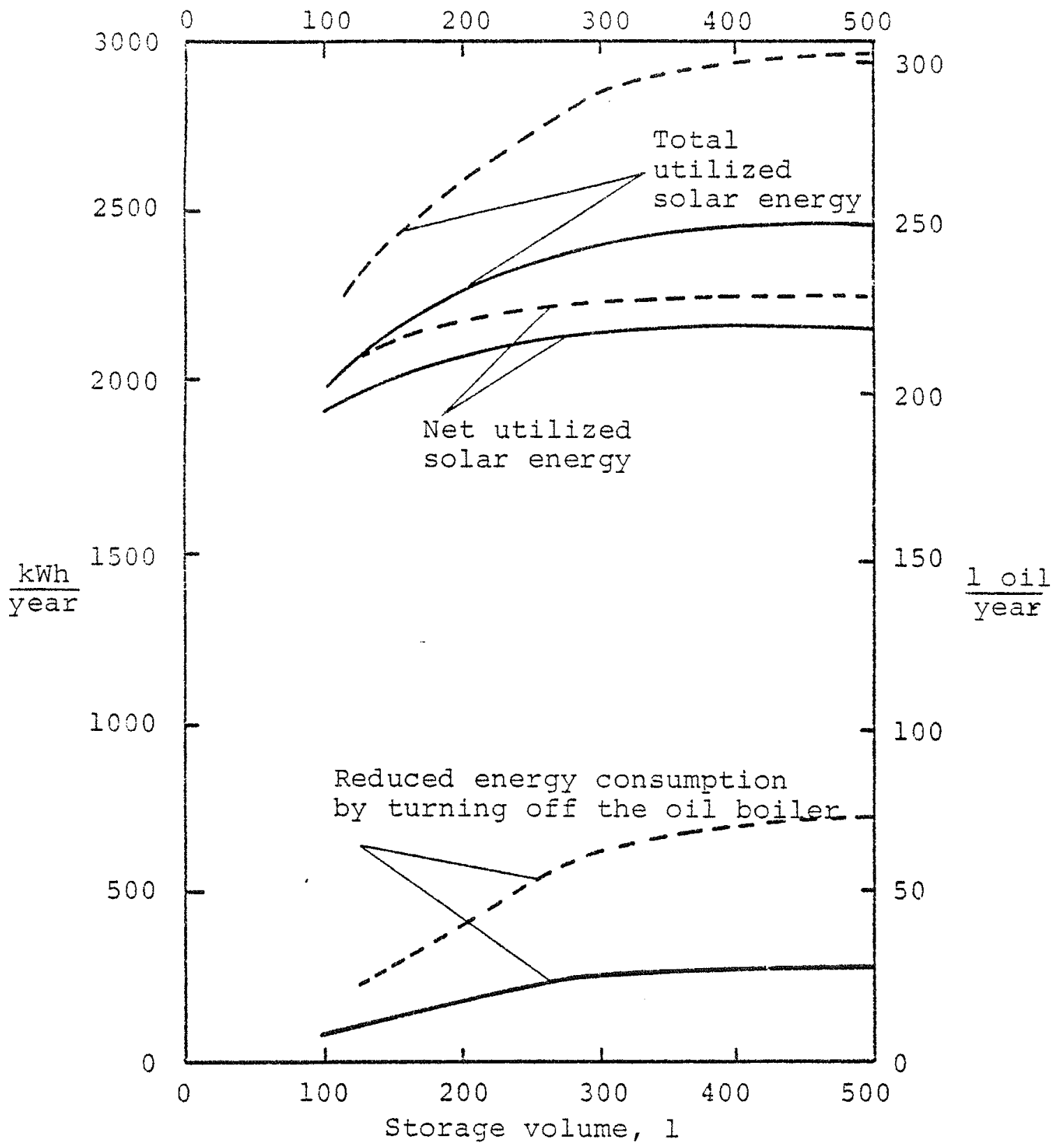

Figure 5. Utilized yearly solar energy from $6 \mathrm{~m}^{2}$ solar heating systems for domestic hot water supply as a function of storage type and storage volume.

Hot water storage:

$\mathrm{Na}_{2} \mathrm{~S}_{2} \mathrm{O}_{3}$ water storage: 
since it is possible to turn off the oil burner in periods where the solar heating system supplies all the wanted water at $45^{\circ} \mathrm{C}$. In this example the number of days with the oil burner turned off is chosen as the number of days in unbroken periods longer than one week, where the solar heating system produces all the wanted water at $45^{\circ} \mathrm{C}$. The number of days with the oil burner turned off, and with that the reduced energy consumption from the oil fired boiler, increases for increasing storage capacity. Therefore the saved energy increases for increasing storage volume, and therefore the $\mathrm{Na}_{2} \mathrm{~S}_{2} \mathrm{O}_{3}$ water storage is favourable compared with the hot water storage as it appears from figure 5.

In this example the total yearly solar energy from the solar heating systems increases for increasing storage volume, and the total solar energy from the $\mathrm{Na}_{2} \mathrm{~S}_{2} \mathrm{O}_{3}$ water storage solar heating system is greater than from that of the hot water storage. Additionally the advantage by using the salt water storage depends on the costs of the different solar heating systems. Figure 6 shows an example of the total yearly utilized solar energy per cost of investment for the solar heating systems as functions of the storage type and the storage volume. The maximum of each curve gives with the used assumptions the best volume of the storage. In this example the best storage volume for both storages is 3001 , and the total yearly utilized solar energy per cost of investment is about $6 \%$ greater for the $\mathrm{Na}_{2} \mathrm{~S}_{2} \mathrm{O}_{3}$ water storage than for the hot water storage.

\section{Conclusion}

With the extra water principle a reliable, stable and relatively inexpensive heat of fusion storage making use of an incongruently melting salt hydrate as storage material can be constructed. The advantage by using a salt water storage instead of a hot water storage in solar heating systems is the great heat storage capacity which involves small demands for storage volume. For solar heating systems with the same yearly net utilized solar energy, the salt water storage volume is about half the water storage volume. For solar heating systems 


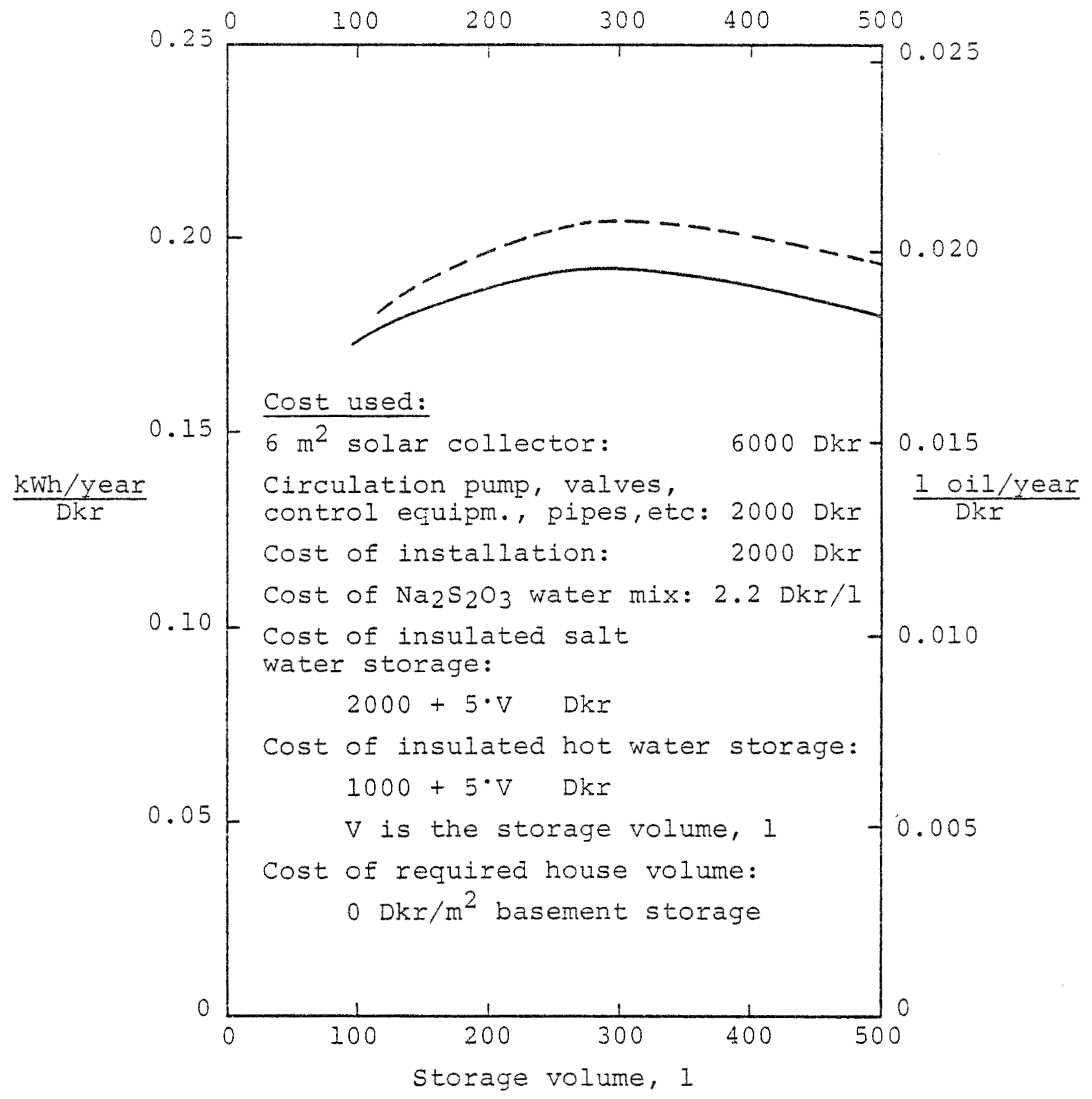

Figure 6. Yearly utilized solar energy per cost of investment for a $6 \mathrm{~m}^{2}$ solar heating system as a function of storage type and storage volume.

$\mathrm{Na}_{2} \mathrm{~S}_{2} \mathrm{O}_{3}$ water storage:

Hot water storage: 
for domestic hot water supply, salt water storages with a suitable melting point are able to supply all the wanted hot water in the summertime during longer periods than ordinary hot water storages. This fact makes the salt water storages particularly favourable in domestic hot water supply systems with an auxiliary energy source which during the summer have a large energy consumption compared with the energy demands for the hot water supply.

\section{Litterature references}

[1] "Report on heat storage in a solar heating system using salt hydrates". S. Furbo and S. Svendsen. Thermal Insulation Laboratory, Technical University of Denmark, July 1977, revised February 1978.

[2] "Investigation of heat storages with salt hydrate as storage medium based on the extra water principle". S. Furbo. Thermal Insulation Laboratory, Technical University of Denmark, December 1978. 


\section{Project organization}

Board of directors:

The Ministry of Energy has selected the following group for the project:

V. Korsgaard, Thermal Insulation Laboratory (chairman)

J. Lemming, civ.eng., the Ministry of Energy

V. Bruhn, secretary of the Board of Energy

J. Fischer, civ.eng.

E. Pedersen, ass. prof., H.C. Ørsted Institute

o. Paulsen, civ.eng., the Technological Institute

J.S.R. Nielsen, civ.eng., Birch \& Krogboe

M. Michelsen, ass. prof., Department of Chemical Enqineering Niels Gram, civ.eng., the Federation of Danish Industries o. Rathman, civ.eng., the Research Station Ris $\varnothing$

\section{Scientific staff from}

the Thermal Insulation Laboratory, the Technical University of Denmark:

P. Christensen, M.Sc. in chemical engineering

S. Furbo, civ.eng.

K.K. Hansen, civ.eng.

P.N. Hansen, ass.prof., project leader

Jan Erik Larsen, civ.eng.

A. Nielsen, civ.eng.

L. Olsen, civ.eng.

Bo sфgaard, civ.eng. 


\section{List of published reports:}

No. 1. Iitteraturunders $\phi g e l s e$ og vurdering af kemiske varmelagre. Peter I. Christensen, august 1979.

No. 2. Sæsonlagring af varme i store vandbassiner. Dipco Engineering Aps, november 1979.

No. 3. Beregning af energiforbrug $i$ bygninger (EFB-1). En metode til brug for bordregnemaskiner. Lic.techn. Anker Nielsen, februar 1980.

No. 4. Beregning af energiforbrug i bygninger (EFB-1). Brugervejledning for TI-59. Lic.techn. Anker Nielsen, februar 1980.

No. 5. Prфvning af varmelagerunits til solvarmeanlæg. Simon Furbo, april 1980.

No. 6. Beregning af ruminddelte bygningers energiforbrug. Anker Nielsen, oktober 1980 .

No. 7. Vinduets betydning for enfamiliehuses energiforbrug. Anker Nielsen, november 1980 . 